\title{
Experimental Study of Mean Flow Characteristics in the Near Field of Wedge-Shaped Swirling Jets
}

\author{
Md. Mosharrof Hossain, Muhammed Hasnain Kabir Nayeem, and Md. Abu Taher Ali
}

\begin{abstract}
In this investigation experiment was carried out in $80 \mathrm{~mm}$ diameter swirling pipe jet, where swirl was generated by attaching wedge-shaped helixes in the pipe. All measurements were taken at $\operatorname{Re} 5.3 e 4$. In the plain pipe jet the potential core was found to exist up to $\mathrm{x} / \mathrm{D}=5$ but in the swirling jet there was no existence of potential core. The mean velocity profiles were found to be influenced by the presence of wedgeshaped helixes in the pipe. The velocity profiles indicated the presence of sinusoidal flow field in the radial direction existed only in the near field of the jet. This flow field died out after $\mathrm{x} / \mathrm{D}=\mathbf{3}$ and the existence of jet flow diminished after $\mathbf{x} / \mathrm{D}=5$.
\end{abstract}

Index Terms - Swirling, Wedge-shaped, Sinusoidal, Helix, Saddle-shaped.

\section{INTRODUCTION}

Swirling jet is one of the most common flow field occurred in nature and used extensively in varieties of engineering applications. Tornadoes, whirlpool, flow around the bluff bodies etc., are the examples of natural swirl flow. Its use in industrial applications are, propulsion system, such as jet engines, burners etc. In combustion devices one of the major problems is to stabilize the flow and this is done by creating strong swirling flow in the combustion chamber. Its peculiar property of creating reverse flow near the nozzle provides reliable stabilization of the flame. In chemical reactors and mixing chambers, faster spreading of the swirling jets relative to the non-swirling ones, plays a major role and leads to a larger entrainment of the surrounding media. Thus, the naturally occurring swirling flows have to be carefully studied in order to forecast and prevent catastrophes. And the characteristics of different types of swirling flows should be known in detail for their efficient use in engineering applications.

Swirling flow itself is complex in nature, further depending on its method of generation and the boundary condition, characteristics of swirling flows are different from one another. Because of its practical and theoretical importance, numerous experimental investigations, computational modeling and more recently direct numerical simulations (DNS) and large eddy simulation (LES) of these flow have been reported in the literature of Kitoh [1],

Published on October 9, 2020.

Md. Mosharrof Hossain, City University, Bangladesh.

(e-mail: mosharrof17@yahoo.com)

Muhammed Hasnain Kabir Nayeem, Military Institute of Science and Technology (MIST), Bangladesh.

(e-mail: hasnain@cse.mist.ae.bd)

Md. Abu Taher Ali, Military Institute of Science and Technology (MIST), Bangladesh.

(e-mail: matali@ae.mist.ac.bd).
Orlandi [2] and Jones [3]. Experimental and numerical studies provide useful information and insight into the flow physics and computational methods involving turbulence modeling offers the broadest prospect of industrial applications. However, the complex flow structure invalidates some of the assumptions which are used in simple turbulence models. Considering the importance of the flow field in its efficient use in industrial applications further experiments should be carried on finding out useful information, which can be used to upgrade these models.

Gupta [4] studied the basic physics of swirling flows is presented in his monograph. Alekseenko [5] theoretically analysis the helical vortices appearing in swirling flows. Kravtsov [10] experimentally studied the turbulent transport in the initial region of swirling turbulent jets. They found with introduction of swirl the vortex core is breaking down and jet mixing occurs with surrounding earlier. Leclaire [11] on their experimental study of High-Reynolds number swirling jet, found unsteadiness in the origin of the developed turbulence at the jet exit by using rotating honeycomb device. Pashtrapanska [9] used 50mm diameter rotating pipe containing $4 \mathrm{~mm}$ outer diameter honeycomb pipe. Depending on the process of swirl generation and boundary variables, flow characteristics differ accordingly. Detailed studies of swirling flow of different geometries and configurations, swirling pipe jets of different initial conditions and different swirl generating method were done in the past by Imao [6], Hirai [7], Islam [8] and are being carried out these days with the hope to find some new information of these types of flow field.

In the present investigation five $80 \mathrm{~mm}$ diameter and $210 \mathrm{~mm}$ long pipe nozzle were used in the experiment. One was plain pipe nozzle and the remaining four were screwed type pipe nozzle of $15^{\circ}, 30^{\circ}, 45^{\circ}$ and $60^{\circ}$ helix angle. Helixes were of wedged shaped type with $60^{\circ}$ apex angle and $27.5 \mathrm{~mm}$ height.

\section{EXPERIMENTAL SETUP}

The experimental study was carried out in a nozzle flow facility of air having the flow controller, fan unit, vibration isolator, silencer diffusers, settling chambers and finally the flow nozzle as shown in Fig. 1. The system air was supplied by the $40 \mathrm{~mm}$ woods variable speed axial flow fan (U.K). The air flow velocity in the nozzle could be regulated both by regulating the fan speed and/or by the flow controller. The overall length of the set up was $8.1 \mathrm{~m}$.

Air entered the fan through the flow controller valve. The silencer was fitted at the discharge of the fan to reduce the noise generated at the fan discharge. Flow from the silencer passed through a $6^{\circ}$ diffuser and wire-screen to the first 
settling chambers. All that were used to breakdown the large eddies generated at the fan discharge and to ensure axial flow. Air from this chamber flowed to the second settling chambers through a nozzle and the second settling chamber where also wire screen and flow straightener were used to ensure axial flow free from large eddies which might be left in the upstream side of the flow. Finally, low turbulence level air discharged through the $80 \mathrm{~mm}$ nozzle. An $80 \mathrm{~mm}$ diameter and $210 \mathrm{~mm}$ long plain pipe and pipes with wedgeshaped helixes of $15^{\circ}, 30^{\circ}, 45^{\circ}$ and $60^{\circ}$ helix angle is shown in Fig. 2 were attached to the discharge of the nozzle exit one after another to get the desired flow field of this investigation.

The axial mean velocity and flow angles both in horizontal and vertical planes were measured by five tube yaw meters made from $1 \mathrm{~mm}$ diameter stainless steel tube. Before taking measurements, the yaw meter calibrated using standard calibration process [12]. Yaw meter readings were taken with selector switch and micro manometer (Furness control U.K.). The exit centerline velocity of the nozzle in the flow direction was taken as the positive $\mathrm{x}$-axis and the radial direction pointing upward as the positive $y$-axis and the direction perpendicular to the $\mathrm{x}-\mathrm{y}$ plane as the $\mathrm{z}$-axis as shown in Fig. 3. To measure and collect data at different $x-y$ locations of the jet a three co-ordinate traversing mechanism was used for mounting and positioning the yaw meter at different $x-y$ locations of the jet.

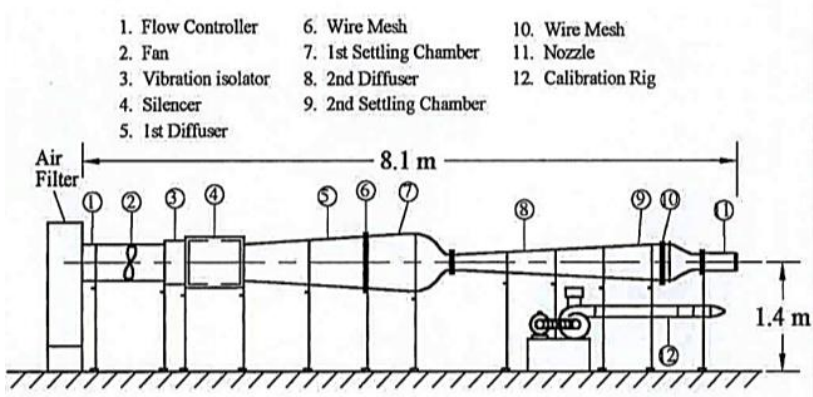

Fig. 1. Experimental setup.

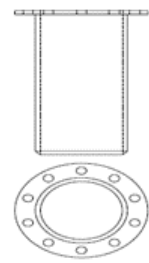

(a)

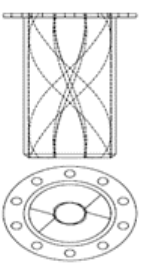

(b)

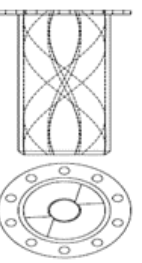

(c)

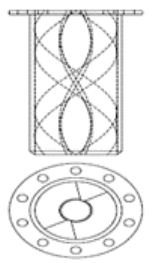

(d)

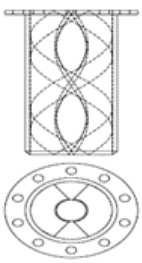

(e)
Fig. 2. Pipe nozzles, (a) plain, (b) $15^{\circ}$ swirl, (c) $30^{\circ}$ swirl, (d) $45^{\circ}$ swirl, (e) $60^{\circ}$ swirl.

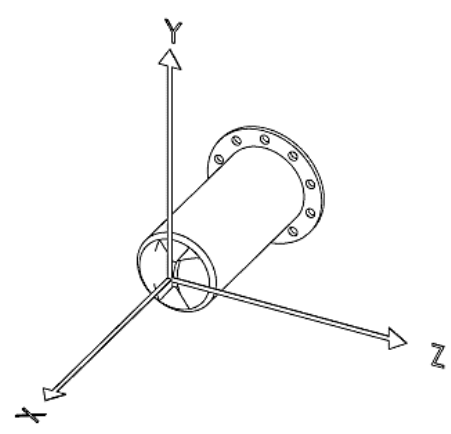

Fig. 3. Co-ordinate system.

\section{RESUlTS AND DISCUSSION}

Before taking readings symmetry of the pipe jet flow was checked. After several adjustment of the measuring system $2 \%$ variation for plain jet and 3\% variation for swirling pipe jets were accepted and readings at different downstream locations were recorded in the $x-y$ and $x-z$ planes. In the measurements Reynolds number was based on the pipe diameter, exit velocity and viscosity of the air at standard atmospheric condition. All measurements were taken at Reynolds number of $5.3 \mathrm{e} 4$.

To observe the effect of swirl on the plain jet its mean velocity profiles are shown in Fig. 4. All the profiles up to $\mathrm{x} / \mathrm{D}=5$ indicated the constant centerline velocity, and this indicates the length of the potential core. The saddle shaped flat zone of these curve decreases in the flow direction and ultimately diminishes at $\mathrm{x} / \mathrm{D}=5.0$. this type of behavior of the profiles was also found in the works of other researcher Islam [8], Kravtsov [10], Van Der Hegge [13], Floss [14].

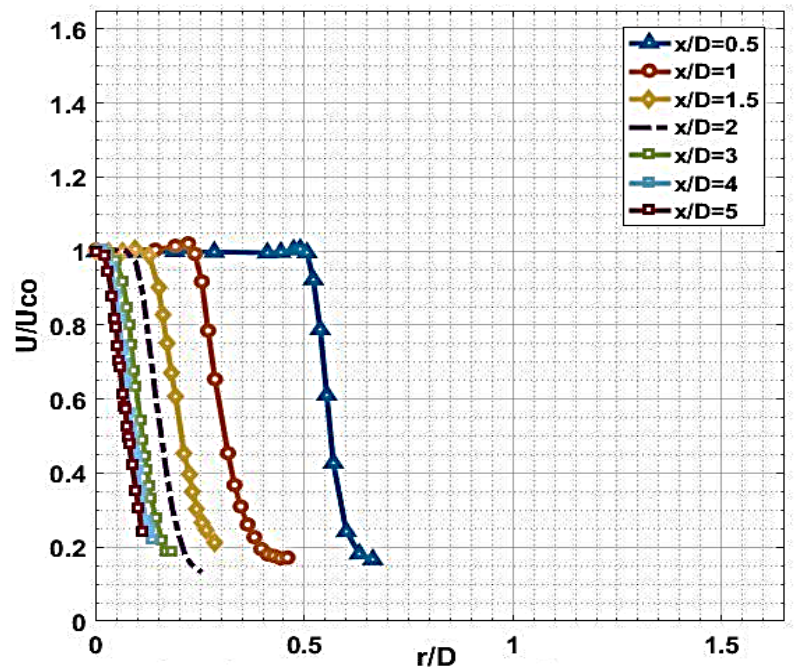

Fig. 4. Axial mean velocity profiles of plain pipe jet.

Due to the presence of wedge-shaped helixes flow characteristics in different angular positions of the $x-y$ plane are different. In the present investigation mean flow characteristics only in the vertical and horizontal planes are studied. In the present experimental set up vertical plane experiences the plane behind the helix and horizontal plane in between the two helixes.

In vertical plane axial mean velocity profiles for $15^{\circ}, 30^{\circ}$, $45^{\circ}$ and $60^{\circ}$ swirl are shown in Fig. 5a, 5b, 5c and 5d respectively. In this plane profiles at different $\mathrm{x} / \mathrm{D}$ locations and for different swirl angles exhibits similar characteristics whose variations increases with the increase of the swirl angle. As height of the wedge is $27.5 \mathrm{~mm}$, there is a clear central zone of jets up to $\mathrm{r} / \mathrm{D}=0.154$ where influence of the swirl is minimum. Velocities in this zone decreases gradually to their minimum values both due to the presence of the wedge and low swirl affect. With the increase of radial distance swirl effect on mean velocity increases producing high velocity field in the zone $r / D=0.5$ to 0.75 for $15^{\circ}$ swirl, $\mathrm{r} / \mathrm{D}=0.35$ to 0.60 for $30^{\circ}$ swirl, $\mathrm{r} / \mathrm{D}=0.35$ to 0.50 for $45^{\circ}$ swirl and finally $\mathrm{r} / \mathrm{D}=0.50$ to 1.0 for $60^{\circ}$ swirl. With the increase of swirl angle velocity maxima in this zone are found to increase and the profiles spread out in the radial direction. In the plain jet while the potential core exists up to 
$\mathrm{x} / \mathrm{D}=5$, in the swirling jets flow field itself is dispersed within it.

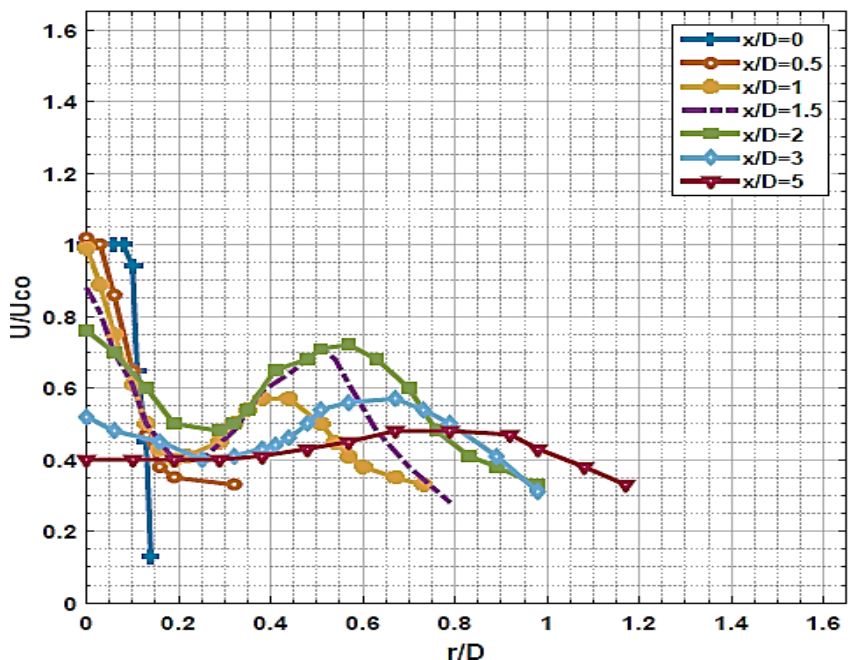

(a)

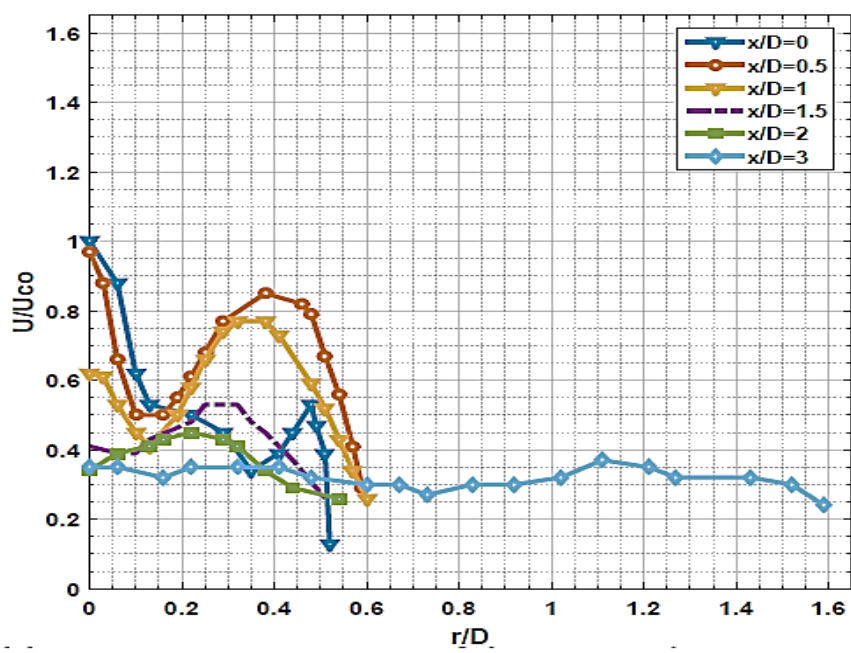

(c)

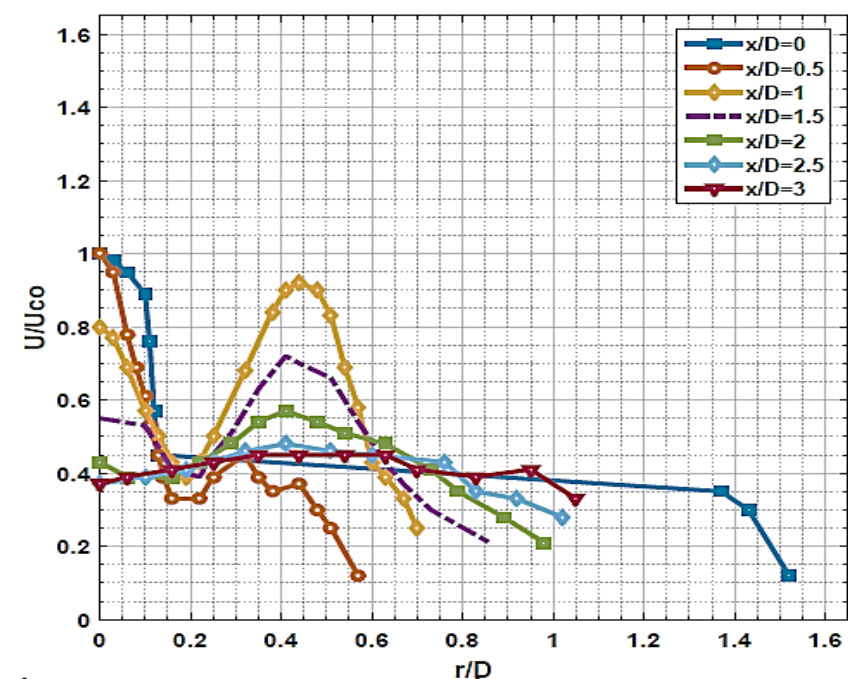

(b)

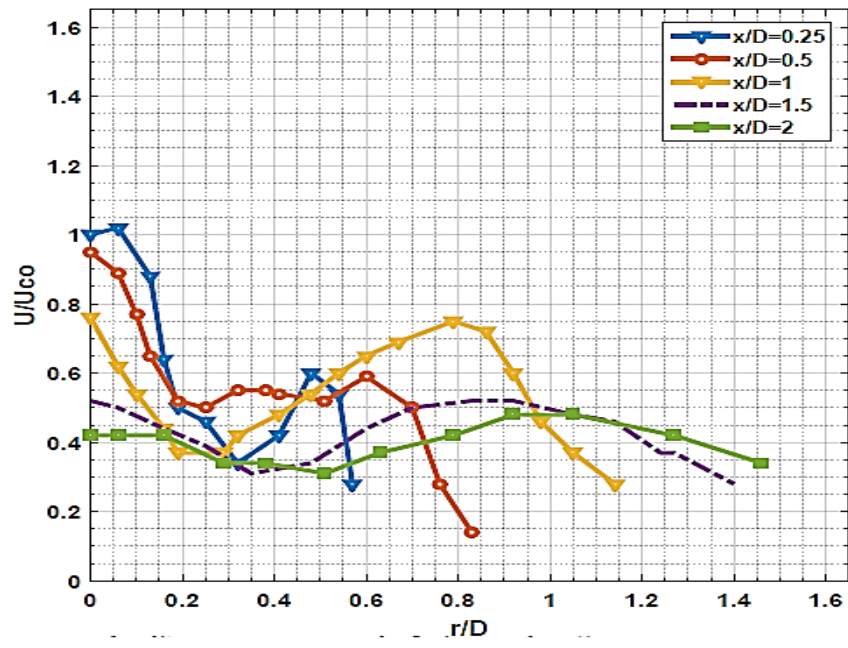

(d)

Fig. 5. Axial mean velocity profiles in the vertical plane, (a) $15^{\circ}$ swirl, (b) $30^{\circ}$ swirl, (c) $45^{\circ}$ swirl, (d) $60^{\circ}$ swirl.

In the present investigation horizontal plane lies in the curved passage in between the two helixes. Velocity profiles in this plane for $15^{\circ}, 30^{\circ}, 45^{\circ}$ and $60^{\circ}$ swirl are shown in Fig. $6 \mathrm{a}, 6 \mathrm{~b}, 6 \mathrm{c}$ and $6 \mathrm{~d}$ respectively. Profiles in this plane also exhibits the increasing influence of swirl with the increase of helix angle. For $15^{\circ}$ swirl, profiles near the exit up to $\mathrm{x} / \mathrm{D}=2.5$, show nearly uniform flow indicating little influence of swirl. Further in the downward direction influence of swirl and low velocity of the vertical plane become prominent on the profiles of this plane. Due to these effects profiles in general take the sinusoidal form before decaying in the radial direction.

\section{CONCLUSION}

The axial mean velocity field of swirling pipe jets with $15^{\circ}, 30^{\circ}, 45^{\circ}$ and $60^{\circ}$ swirl have been studied experimentally. To understand the effect of swirl, a set of measurements on plain pipe jet have also been taken. Experimental results of this work and its analysis show some critical features. Some of which are similar to and some are different from other related works of Kitoh [1],
Gupta [4], Islam [8], Kravtsov [10] and Sharma [15].

In circular pipe jet potential core exists up to $\mathrm{x} / \mathrm{D}=5$ while that does not exist in the swirling pipe jet. Further, swirling pipe jets are found to disperse asymptotically after $\mathrm{x} / \mathrm{D}=5$. In the main flow zone ( $\mathrm{x} / \mathrm{D}=0$ to 2.5 ) velocity profiles in general, exhibit the sinusoidal form of different strengths for different degrees of swirl. By examining the characteristics of the velocity profiles both in the vertical and horizontal planes it may be concluded that a sinusoidal nature of flow field exists in the vertical plane of swirling jets of this experiments, and this flow field quickly dies out after $\mathrm{x} / \mathrm{D}=3$. 


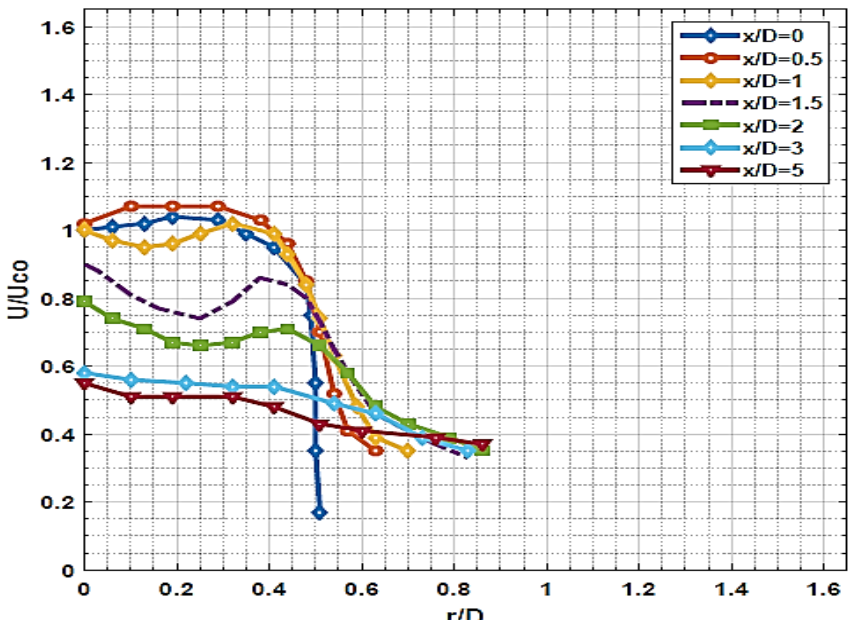

(a)

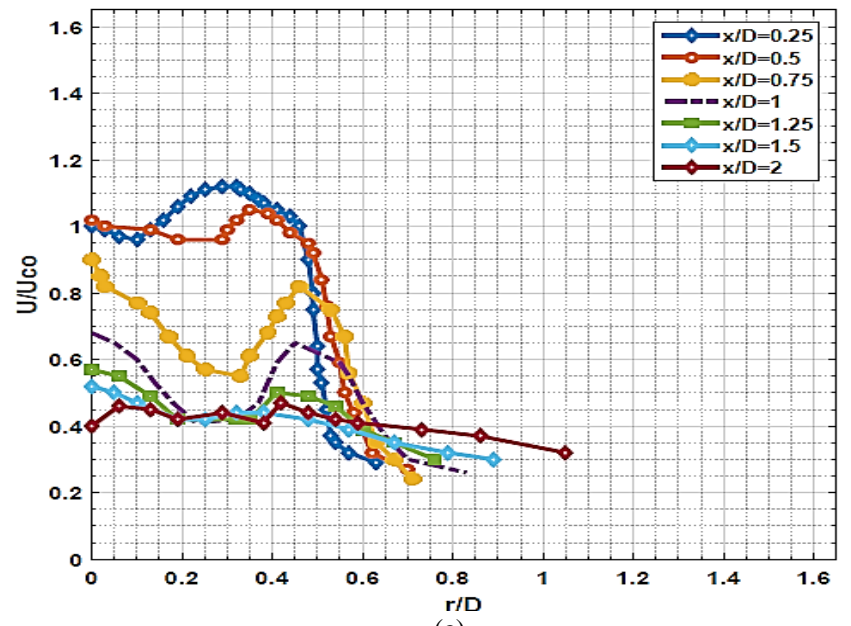

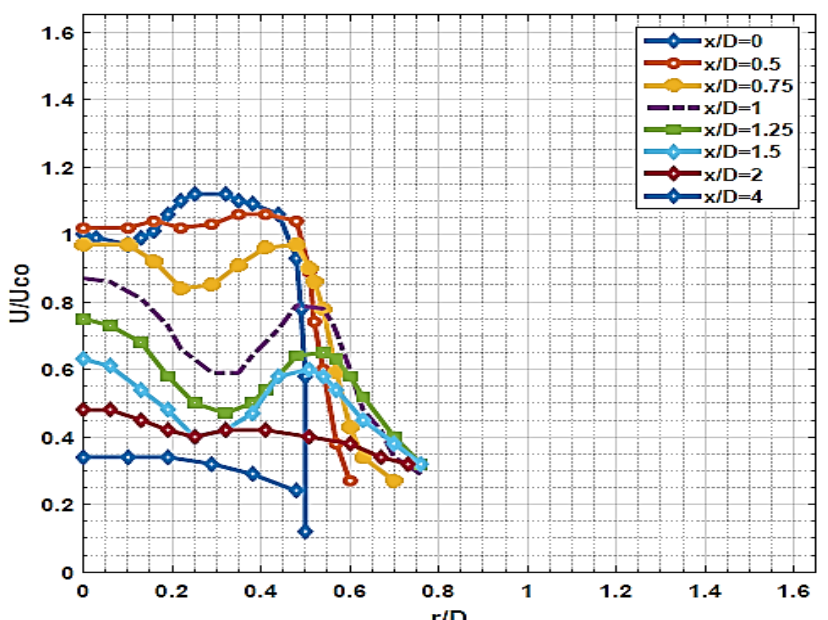

(b)

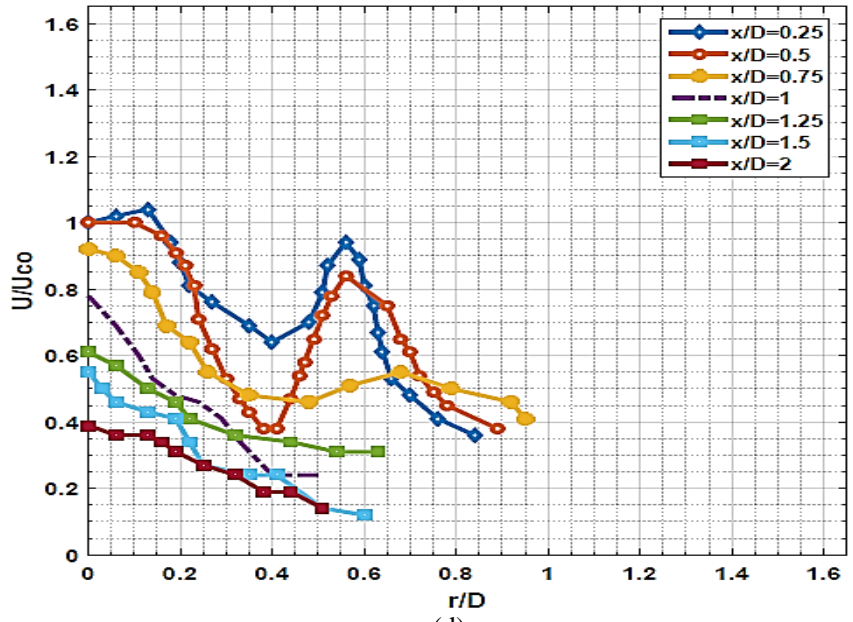

(d)

Fig. 6. Axial mean velocity profiles in the horizontal plane, (a) $15^{\circ}$ swirl, (b) $30^{\circ}$ swirl, (c) $45^{\circ}$ swirl, (d) $60^{\circ}$ swirl.

\section{REFERENCES}

[1] O. Kitoh, "Experimental study of turbulent swirling flow in a straight pipe," Journal of Fluid Mechanics, vol. 225, pp. 445-479, 1991

[2] P. Orlandi and M. Fatica, "Direct simulations of turbulent flow in a pipe rotating about its axis," Journal of Fluid Mechanics, vol. 343, pp. 43-72, 1997.

[3] W. P. Jones and A. Pascau, "Calculation of confined swirling flows with second moment closure," Journal of Fluid Mechanics, vol. 111, pp. 57-63, 1989.

[4] A. Gupto, D. G. Lilley and N. Syred, "Swirl flows," Abacus Presss, kent, England, 1984.

[5] J. V. Alekseenko, P. A. Kuibin, V. S. Okulov and S. I. Shtork, "Helical vortices in swirl flow," Journal of Fluid Mechanics, vol. 382, pp. 145-243, 1999.

[6] S. Imao, M. Itoh and T. Harada, "Turbulent characteristics of the flow in an axially rotating pipe flow," International Journal of Fluid Flow, vol. 17 , no. 5 , pp. 444-451, 1996.

[7] S. Hirai, T. Takagi and M. Matsumoto, "Prediction of the laminarization phenomena in an axially rotating pipe flow," Journal of Fluid Mechanics, vol. 110, pp. 424-430, 1988.

[8] M. T. Islam, "Flow characteristics of unexcited and excited circular wedge-shaped jets," Ph.D. dissertation, Dept. Mecha. Eng., Bangladesh University of Engineering and Technology, Dhaka, Bangladesh, 1995.

[9] M. Pashtrapansha, J. Jovanovic, H. Lienhart and F. Durst, "Turbulent measurements in a swirling pipe flow," Experiments in Fluids, vol. 41, pp. 813-827, 2006

[10] Z. D. Kravtsov D. K. Sharaborin and V. M. Dulin, "Swirl effect on flow structure and mixing in a turbulent jet," Journal of Physics, vol. 980, 2018.

[11] B. Leclaire and L. Jacquin, "On the generation of swirling jets: high Reynolds-number rotating flow in a pipe with a final contraction," Journal of Fluid Mechanics, vol. 692, pp. 78-111, 2012.

[12] D. W. Bryer and R. C. Pankhurst, "Pressure probe methods for determining wind speed and flow direction," National Physical Laboratory, London, England, 1971.
[13] B. G. Van Der Hegge, "Measurement of the velocity distribution in plain turbulent jet of air," Applied Scientific Research, vol. 7, no. A, pp. 256-276, 1958

[14] J. F. Floss and J. B. Lones, "Secondary effects in a bounded rectangular jet," Journal of Basic Engineering, vol. 90, 1968.

[15] R. Sharma and F. Cozzi, "Experimental study of unconfined and confined isothermal swirling jets," International Journal of Mechanical and Mechatronics Engineering, vol. 11, no.2, pp. 386396, 2017.

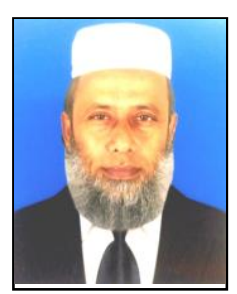

Md. Mosharrof Hossain is an Assistant Professor of the department of Mechanical Engineering at City University, Savar, Dhaka, Bangladesh. He did his $\mathrm{PhD}$ in Mechanical Engineering from Bangladesh University of Engineering and Technology (BUET), Dhaka, Bangladesh (2003). His Master of Science is in Mechanical Engineering, BUET, Dhaka, Bangladesh (1991). His Bachelor of Science in Mechanical Engineering, DUET, Dhaka, Bangladesh (1985). He has over 30 years' experience in mechanical engineering for Roads and Highways Department (RHD), Bangladesh.

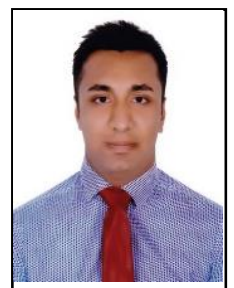

Muhammed Hasnain Kabir Nayeem is pursuing his MSc from department of Aeronautical engineering (AE) in Military institute of science and technology(MIST), Mirpur cantonment, Dhaka Bangladesh. He completed his BSc in aeronautical engineering from MIST, Dhaka Bangladesh.

$\mathrm{V}$. He has 2 years of research experience as a Research assistant in Computer science engineering department, MIST. One of his published books named as title: "Study of circular swirling jet" published by LAP lambert academic publishing, ISBN-978-620-028036-7 


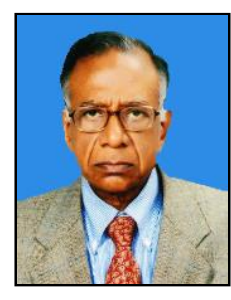

Md. Abu Taher Ali is professor of the department of aeronautical engineering (AE) in Military institute of science and technology (MIST), mIrpur cantonment, Dhaka Bangladesh. $\mathrm{He}$ did his $\mathrm{PhD}$ in mechanical engineering, Imperial college, University of London, England (1980). His masters of science in Mechanical engineering, BUET, Dhaka, Bangladesh \{1972).

His bachelor of engineering, Mechanical engineering, $1^{\text {st }}$ class, $4^{\text {th }}$ position, EPUET, Dhaka (1966). He has over 50 years of teaching experience in the corresponding department. 